they became available the group have gained experience which we wish to communicate to others who may be concerned with the development of multiple screening in the setting of general practice. Many questions have been raised. Even if these are not particularly new we hope by reporting our experience to encourage others to pursue similar or parallel studies focused on some of the following questions.

What is the effect of multiple screening, carried out in the setting of general practice, on the work-load of the practice? Do patients who have been screened consult more or less often as a result ? What kinds of patients consult more or less often after such a screening ? What is the subsequent effect on the doctor's routine diagnostic or therapeutic activity in respect of those patients in whose notes are recorded the results of a multiple-screening examination? What is the short-term or long-term effect on the health of the patient as distinct from the patient's patterns of utilization of medical care ? What kinds of patients do not readily accept an offer of screening ? What changes would occur in the doctor's professional role in a practice in which such screening examinations were carried out routinely and entirely by the deployment of ancillary staff ?

\section{Summary}

Female patients aged 15 years and over in a general practice were invited to take part in a multiple-screening programme.

The procedures comprised a questionary relating to urinary symptomatology, the recording of height, weight, and blood pressure, and the results of a straight $x$-ray film of the chest. Breasts were palpated and a cervical smear was taken. Total viable bacterial counts were carried out on midstream urine specimens. Biochemical tests included estimation of urea, cholesterol, and P.B.I. Blood glucose was estimated by the Dextrostix method. Haematological tests included estimation of haemoglobin, P.C.V., M.C.H.C., E.S.R., and W.B.C.

Of the 2,158 female patients on the practice list the patients' doctors excluded 358 from this survey. The remaining 1,800 were offered the multiple-screening examination. The acceptance rate was $43 \%$.
The most common conditions found at examination were anaemia, bacteriuria, raised blood pressure, obesity, and hypercholesterolaemia.

Three subsidiary studies which have been undertaken as a result of this experience are an assessment of the Dextrostix method of blood glucose estimation in the setting of general practice, the use of the E.S.R. as a screening procedure, and a study of the factors associated with acceptance or nonacceptance of the offer of a health overhaul offered to patients in a general practice.

In this presentation of the first results emphasis is placed on methodology. The advantages and disadvantages of carrying out this kind of exercise in the setting of general practice are discussed. The role of the nurse in accepting a major personal responsibility for a screening programme is emphasized. Areas in which further studies are required are indicated.

This study would not have been possible without the painstaking and enthusiastic support of our secretarial staff. We also acknowledge our gratitude to those patients who collaborated so effectively, particularly in the early days of setting up the study. We welcome the opportunity to acknowledge our indebtedness for the generous assistance so freely given by individuals in other university departments, and in particular the following laboratory and other services: Dr. S. H. Davies, haematology ; Dr. B. I. Davies, bacteriology ; Professor R. J. Kellar, cervical cytology; Dr. Eric Samuel, radiology ; Professor L. G. Whitby, clinical chemistry; and Dr. G. B. Young and the staff of the Family Doctor (Diagnostic) Centre. Mr. W. Lutz and Miss C. Laidlaw, department of social medicine, gave us advice and considerable material assistance in processing the data. Ames Company generously supplied Uristix and Dextrostix reagents.

\section{REFERENCES}

Fowler, P. B. S., and Swale, J. (1967). Lancet, 1, 1077.

Kass, E. H. (1956). Trans. Ass. Amer. Phycns, 69, 56. 1053.

Kemsley, W. F. F. (1951-2). Ann. Eugen. (Lond.), 16, 316.

Kemsley, W. F. F. (1951-2). Ann. Eugen. (Lond.), 16, 316.

Kincaid-Smith, P., and Bullen, M. (1965). Lancet, 1, 395. 732.

Thomas, H." E., jun., Kannel, W. B., Dawber, T. R., and McNamara, P. M. (1966). New Engl. f. Med., 274, 701.

Wilson, J. M. G., and Jungner, G. (1967). The Principles and Practice of Screening for Disease. W.H.O., Geneva.

World Health Organization (1965). Techn. Rep. Ser., No. 310.

\title{
Parietal-cell Antibodies in Patients Undergoing Gastric Surgery
}

\author{
PAMELA M. ASHURST,* M.B., CH.B.
}

The present investigation was undertaken in order to determine whether circulating antibodies to gastric parietal cells (P.C.A.) were detectable by immunofluorescence after surgery to the stomach for various conditions. Circulating antibodies tc cardiac muscle have been demonstrated after myocardial infarction; similarly, thyroid antibodies have been demonstrated in patients with subacute viral thyroiditis, which disappear when the thyroiditis resolves (Kleinsorge et al., 1957-8; Roitt and Doniach, 1958). Surgical trauma to gastric tissue might be thought to have a similar immunizing potential, as might damage by drugs, particularly aspirin.

Studies have shown that about $60 \%$ of patients who have undergone subtotal gastrectomy may develop chronic gastritis or progressive gastric atrophy (Coghill ct al., 1958; Lees and Grandjean, 1958). It is said that these patients have an increased chance of developing pernicious anaemia and carcinoma of the gastric remnant (Welbourn et al., 1956;

* Depariment of Gastroenterology, Frenchay Hospital, Brisiol.
Krause, 1958). Similarly there is an increased incidence of gastric carcinoma in patients with pernicious anaemia (Jenner, 1939). Antibodies to gastric parietal cells are detectable by immunofluorescence in the serum of $80-90 \%$ of patients with pernicious anaemia (Taylor et al., 1962 ; Doniach et al., 1963 ; Coghill et al., 1965) and of some with simple chronic atrophic gastritis (Coghill et al., 1965). It has been suggested that the gastric changes in pernicious anaemia are in some way related to an immune response, but there is no direct evidence that humoral antibodies are pathogenetic in the gastritis of pernicious anaemia, though they may reflect an underlying disturbance of cellular immunity. Circulating P.C.A. of the IgG class have been demonstrated in the blood of babies born to mothers with pernicious anaemia. The infants developed normally, their gastric mucosa apparently remained healthy, and P.C.A. could not be detected in their serum four months after birth (Fisher and Taylor, 1967).

If circulating P.C.A. were detected after surgery, this would support the hypothesis of tissue damage causing the alteration 
of the immune status. Persistence of circulating P.C.A. developing after surgery might be a useful diagnostic aid for selecting those patients at risk of developing pernicious anaemia or gastric carcinoma at a later date.

\section{Patients and Specimens}

A total of 337 specimens of serum from 153 patients were tested for P.C.A. The patients fell into six groups (Table I); of these 153 patients, 51 underwent gastric surgery (Table II). In 48 cases a specimen of blood was obtained preoperatively, and two or three specimens were taken from each patient after surgery at intervals ranging from two days to two years, but mostly in the period eight days to two months after surgery. One of the specimens was taken from each patient between the 11 th and 14 th postoperative days. The remaining three patients had undergone partial gastrectomy for duodenal ulcer respectively 3,7 , and 12 years before the sample was obtained, and had no specific gastric symptoms when seen. A total of 235 specimens of serum were collected from the patients having surgery.

A specimen of serum was tested from each of 28 patients admitted with haemorrhage thought to be due to an acute erosion or erosive gastritis. Of these 28 patients 18 had taken aspirin in some form, 2 phenylbutazone, 1 prednisone, and 7 had no history of drug ingestion.

\section{Method}

The 337 specimens of serum from 153 patients were coded and stored at $-20^{\circ} \mathrm{C}$. They were examined for P.C.A. by the "sandwich" technique (Taylor et al., 1962), fresh frozen normal human stomach obtained at operation from blood group $\mathrm{O}$ patients being used. Burroughs Wellcome commercial preparation of fluorescein-conjugated anti-human gammaglobulia was used at a dilution of $1: 4$ with Coons buffer, after absorption of each $1 \mathrm{ml}$. on $100 \mathrm{mg}$. of pigs' liver powder.

A known positive and a known negative serum were incubated with each batch of sera, which were examined neat and at random. The sera were evaluated as either positive or negative; slides showing equivocal fluorescence were regarded as negative. A Gillett and Sibert Conference microscope with quartz iodine light source was used for microscopy.

\section{Results}

After surgery no P.C.A. were demonstrated in specimens from patients in whom no P.C.A. had been detected in the preoperative specimen of serum. Results are shown in the righthand columns of Tables I and II. Of 18 patients with clinically proved pernicious anaemia $15(83.3 \%)$ showed evidence of circulating P.C.A., and P.C.A. were found in the serum of $2(9 \%)$ of the 22 patients with gastric carcinoma, both before and after operation. No P.C.A. were detected in serum from patients with gastric ulcer or acute erosions, and circulating P.C.A. was found in only $1(1.9 \%)$ of 53 patients with duodenal ulcer.

TABLE I.

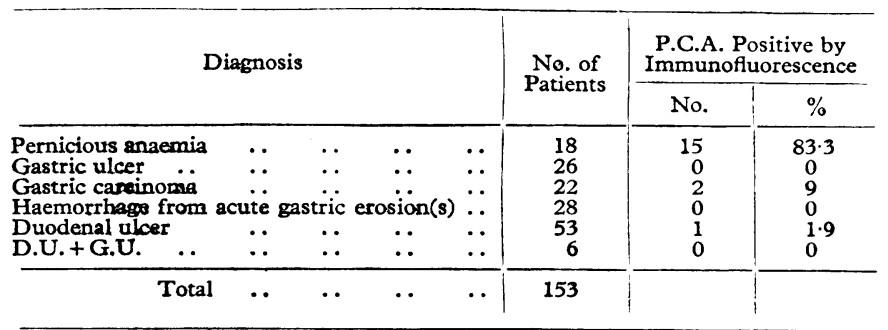

TABLE II.

\begin{tabular}{|c|c|c|c|c|c|c|}
\hline \multirow{2}{*}{\multicolumn{4}{|c|}{ Operation }} & \multirow{3}{*}{$\begin{array}{c}\begin{array}{c}\text { No. of } \\
\text { Patients }\end{array} \\
7 \\
93 \\
2\end{array}$} & \multicolumn{2}{|c|}{ No. of P.C.A. Positive } \\
\hline & & & & & \multirow{2}{*}{$\begin{array}{c}\text { Preop. } \\
1^{*} \\
0 \\
2 \dagger \\
0\end{array}$} & \multirow{2}{*}{$\begin{array}{c}\text { Postop. } \\
1 \\
0 \\
2 \\
0 \\
\end{array}$} \\
\hline $\begin{array}{l}\text { Vagotomy and pyloro } \\
\text { Gastroenterostomy o } \\
\text { after vagotomy and } \\
\text { Antrectomy or partial } \\
\text { Total gastrectomy }\end{array}$ & $\begin{array}{l}\text { last } \\
\text { reo } \\
\text { pylo } \\
\text { gast } \\
. . \\
\end{array}$ & $\begin{array}{l}\text { ersion } \\
\text { plasty } \\
\text { tomy } \\
. \\
\end{array}$ & 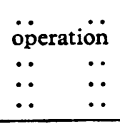 & & & \\
\hline Total & .. & .. & . & 51 & 3 & 3 \\
\hline
\end{tabular}

\section{Discussion}

Gastric parietal-cell antibodies may be detected by the immunofluorescent technique in the serum of between 2 and $19 \%$ of healthy persons, increasing in frequency with age, particularly in women (Taylor et al., 1962; Irvine, 1963). The incidence of $83.3 \%$ P.C.A. found in patients with pernicious anaemia is in accordance with previously published figures. Two of 22 patients with gastric cancer showed circulating P.C.A., an incidence of $9 \%$, which is similar to that obtained for a series of 67 patients investigated by Kravetz et al. (1967). The finding of only one patient with duodenal ulcer to have circulating P.C.A., an incidence of $1.9 \%$, is below that which might be expected in the normal population. This patient also had a hiatus hernia with an associated gastritis, so that no conclusions regarding the significance of this finding can be drawn. No histological assessment of the gastritis is available. All the patients with duodenal ulcer in this series were given an augmented histamine test; most were hypersecretors and none was achlorhydric.

A surprising finding was the absence of P.C.A. in 26 patients with gastric ulcer and in six patients with the combined pathology of gastric ulcer and duodenal ulcer, particularly as patients with gastric ulcer are often hyposecretors. In fact the incidence of P.C.A. detected in the group of patients under investigation, with the exception of the groups with pernicious anaemia and gastric cancer, was below the normal range, allowing for age and sex (Irvine, 1963).

The greatly increased incidence of P.C.A. in patients with pernicious anaemia is perhaps genetically determined. Kravetz et al. (1967) have shown that the severity of chronic gastritis, indistinguishable histologically from the atrophic gastritis of pernicious anaemia, is not simply related to the presence of parietal-cell antibodies. Microscopical findings in the gastric mucosa of patients with serological evidence of autoimmune response do not differ greatly from those in post-gastrectomy patients of chronic gastritis patients, without circulating P.C.A. (Fisher et al., 1967).

No circulating P.C.A. were detected after trauma to the stomach by surgery or by drugs which had been ingested by 21 out of 28 patients admitted with haemorrhage from an acute gastric erosion or erosive gastritis. This latter group of patients were shown to be achlorhydric at the time of the haemorrhage (C. E. R. Thompson, personal communication, 1967). The exact relation between P.C.A. production and damage to the gastric mucosa remains unknown. The results of the present study lend no support to the hypothesis that production of circulating P.C.A. is a response to the release of antigenic material from damaged gastric mucosa.

\section{Summary}

Preoperative and serial postoperative specimens of serum from 51 patients undergoing gastric surgery for various pathological conditions were examined for antibodies to gastric parietal cells (P.C.A.), using the immunofluorescent "sand- 
wich" technique. In no case were circulating P.C.A. detected postoperatively that had not been found in the preoperative specimen. The incidence of P.C.A. was below the normal range for the age and sex of the patients, but 2 of $22(9 \%)$ patients with gastric cancer showed circulating P.C.A.

The failure to demonstrate circulating parietal-cell antibodies in serial specimens of serum taken from patients who had undergone gastric surgery does not support the hypothesis that autoimmunization is the result of damage to the gastric mucosa.

My thanks are due to Mr. T. J. Butler, who suggested this investigation; to Burroughs Wellcome, who kindly gave the fluorescein-labelled anti-human gammaglobulin used in this study; and particularly to Dr. W. J. Harrison for his interest, help, and constructive criticism, without which this work would never have been possible. I wish to acknowledge the financial assistance of the S,W. Regional Hospital Board Research Fund in supporting my work.

\section{REFERENCES}

Coghill, N. F., Doniach, D., Roitt, I. M., Mollin, D. L., and Williams, A. W. (1965). Gut, 6, 48.

Coghili, N. F., and Williams, A W. (1958). Proc. roy. Soc. Med., 51, 464.

Doniach, D., Roitt, I. M., and Taylor, K. B. (1963). Brit. med. F., 1, 1374 .

Fisher, June Marion, Mackay, I. R., Taylor, K. B., and Berta Ungar (1967). Lancet, 1, 176.

Fisher, June Marion, and Taylor, K. B. (1967). Lancet, 1, 695

Irvine, W. J. (1963). Quart. F. exp. Physiol., 48, 427

Jenner, A. W. F. (1939). Acta med. scand., $102,529$.

Kleinsorge, H., Dornbusch, S., Jäger, D., and Jäger, L. (1957-8). Wiss. Z. Friedrich Schiller-Univ. Jena, 7, 455.

Krause, U. (1958). Acta chir. scand., 114, 341.

Kravetz, R. E., Van Noorden, S., and Spiro, H. M. (1967). Lancet, 1, 235.

Lees, F., and Grandiean, L. C. (1958). Arch. intern. Med., 101, 943.

Roitt, I. M., and Doniach, D. (1958). Lancet, 2,1027

Shiner, M., and Doniach, I. (1957). Gastroenterology, 32, 313

Taylor, K., B., Roitt, I. M., Doniach, D., Couchman, K. G., and Shapland, C. (1962). Brit. med. 7., 2, 1347.

Thompson, C. E. R. (1967), Personal communication.

Welbourn, R. B., Nelson, M. G., and Zacharias, F. J. (1955). Brit. F. Surg., 43, 422 .

\title{
Childhood Splenomegaly in Uganda, and its Relation to Malaria
}

\author{
THERESE M. VANIER,* M.B., M.R.C.P. ; M. S. R. HUTT, $†$ M.D., F.R.C.P., F.C.PATH. \\ G. C. COOK, $\ddagger$ M.D., B.SC., M.R.C.P.
}

Brit. med. F., 1968, 2, 649-653

Splenomegaly of mild degree is common among children in Uganda and in many other tropical and subtropical countries. This may be transient and is usually due to malaria, but it can also be due to other infective illnesses (McGregor et al., 1956 ; Fawdry and Trowell, 1958 ; Edington, 1967). There is a group of children, however, who have a grosser degree of splenic enlargement of long duration in which investigations show no obvious cause. These cases have been called "idiopathic tropical splenomegaly" of childhood, and may be compared with the same syndrome in adults. Recent investigation of idiopathic tropical splenomegaly in Ugandan adults suggests that the majority of such cases are due to malarial infection, though whether this is an altered host response or an infection by a specific type of malaria is still uncertain (Gebbie et al., 1964 ; Marsden et al., 1965). The problem of gross splenomegaly in childhood in Uganda has not hitherto been investigated. This paper reports investigations on 32 children with idiopathic tropical splenomegaly.

\section{Patients and Methods}

Thirty-two children with "very big spleens" were investigated. Their spleens were enlarged to or below the umbilicus, and all had hepatomegaly. The children were aged 4 months to 10 years and belonged to 15 different tribes (Table I); most lived within 20 miles $(32 \mathrm{~km}$.), but some as far as 100 miles $(160 \mathrm{~km}$.) from the hospital. Those with the largest spleens and much cutaneous scarification had the longest histories of splenic enlargement (Fig. 1). In all cases a history of intermittent fever was obtained, but that is so common in Uganda that it is of little significance. There was no history of umbilical sepsis. Jaundice had been noted at some time in seven children, three of whom had sickle-cell disease. In one child severe kwashiorkor, bilateral corneal necrosis, and prolapse of the iris, probably due to vitamin-A deficiency, were present. One had marasmus at the time of admission, and Cases 7 , $12,16,19,23$, and 32 had a history or clinical picture suggesting mild or moderate malnutrition. Case 12 also had osteomyelitis.

* Clinical Haematologist, St. Thomas's Hospital, London S.E.1.

t Professor of Pathology, Makerere University College Medical School, Kampala, Uganda. The pathological aspects of the work were supported by a grant from W.H.O.

¥ Le turer in Medicine, Makerere University College Medical School, Kampala, Uganda. Present address: Department of Medicine, the Royal Free Hospital, London W.C.I.
Three measurements were made to record spleen size: (A) the distance from the xiphisternum to a horizontal line connecting the lowest level of the spleen to the midline, (B) from the midaxillary line to the most medial point of the spleen, and (C) from the costal margin at the nipple-line to the lowest point of the spleen. The sum of $\mathbf{A}$ and $\mathbf{B}$ was used in assessing change in size during follow-up studies. The liver was measured vertically from the right costal margin at the nipple-line to its lowest point.

Haematological investigations, were carried out in all cases by means of standard techniques (Dacie and Lewis, 1963). Thick and thin blood films were examined for malarial parasites on the day of admission, daily throughout the time in hospital (2-30 days, mean 5 days), and at each subsequent outpatient attendance. In 25 children further investigations included stool and urine examination, serum bilirubin, aspartate and alanine aminotransferase, alkaline

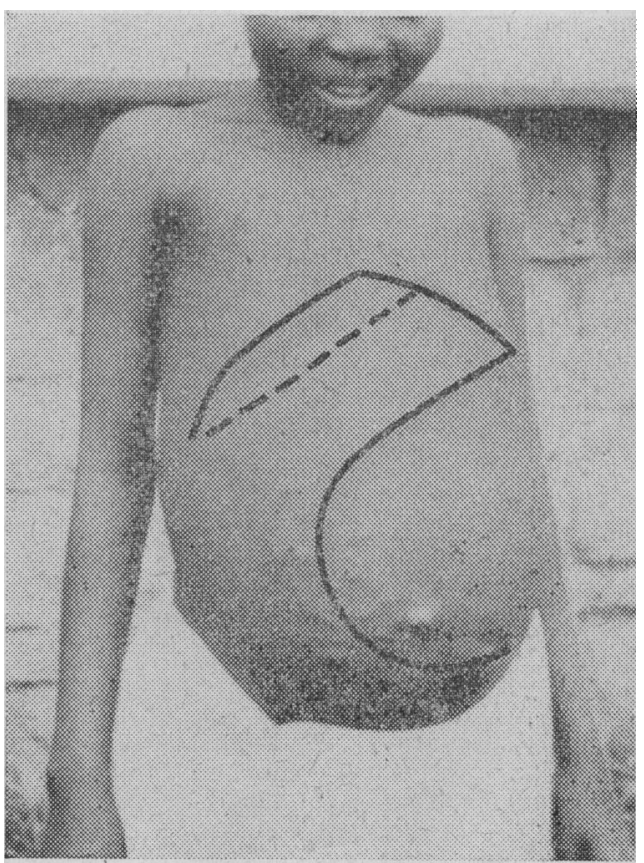

Fig. 1.-Case 32. Gross splenomegaly and cutaneous scarification. 